\section{ECONGTOR}

Make Your Publications Visible.
A Service of

こBW

Leibniz-Informationszentrum Wirtschaft

Leibniz Information Centre

for Economics

Tille, Cédric

\title{
Working Paper \\ On the distributional effects of exchange rate fluctuations
}

Staff Report, No. 146

\section{Provided in Cooperation with:}

Federal Reserve Bank of New York

Suggested Citation: Tille, Cédric (2002) : On the distributional effects of exchange rate fluctuations, Staff Report, No. 146, Federal Reserve Bank of New York, New York, NY

This Version is available at:

http://hdl.handle.net/10419/60620

\section{Standard-Nutzungsbedingungen:}

Die Dokumente auf EconStor dürfen zu eigenen wissenschaftlichen Zwecken und zum Privatgebrauch gespeichert und kopiert werden.

Sie dürfen die Dokumente nicht für öffentliche oder kommerzielle Zwecke vervielfältigen, öffentlich ausstellen, öffentlich zugänglich machen, vertreiben oder anderweitig nutzen.

Sofern die Verfasser die Dokumente unter Open-Content-Lizenzen (insbesondere CC-Lizenzen) zur Verfügung gestellt haben sollten, gelten abweichend von diesen Nutzungsbedingungen die in der dort genannten Lizenz gewährten Nutzungsrechte.
Terms of use:

Documents in EconStor may be saved and copied for your personal and scholarly purposes.

You are not to copy documents for public or commercial purposes, to exhibit the documents publicly, to make them publicly available on the internet, or to distribute or otherwise use the documents in public.

If the documents have been made available under an Open Content Licence (especially Creative Commons Licences), you may exercise further usage rights as specified in the indicated licence.

\section{UUW.ECONSTOR.EU}




\title{
On the Distributional Effects of Exchange Rate Fluctuations
}

\author{
Cédric Tille \\ Federal Reserve Bank of New York *
}

February 10, 2002

\begin{abstract}
The paper studies the differential impact of exchange rate fluctuations on households in a country. I extend earlier research by relaxing the assumption of complete international sectoral specialization. My setup allows for the presence of several different sectors in a given country, each producing a different type of good. Combined with incomplete asset markets, the sectoral dimension leads to a heterogenous impact of exchange rate fluctuation within each country. In particular, although a depreciation of a country's currency has an adverse "beggar-thyself" effect for the country as a whole, a minority of households benefit.

Keywords: welfare, exchange rate fluctuations, international competitiveness.

JEL classification: F31, F41, F42
\end{abstract}

*Email: cedric.tille@ny.frb.org. I thank Brian Doyle, Paolo Pesenti, and seminar participants at the 2001 meeting of the American Economic Association, the 2001 meeting of the European Economic Association, the Swiss Society of Economics and Statistics, the Federal Reserve Bank of New York, Tilburg University, the European Central Bank and the University of Munich for valuable comments. The views expressed in this paper are those of the author and are not necessarily reflective of views at the Federal Reserve Bank of New York or the Federal Reserve System. 


\section{Introduction}

The assessment of the international spillovers of monetary policy through exchange rate fluctuations as received renewed attention in the literature. This renewal has been spurred by the micro-founded general equilibrium setup introduced by Obstfeld and $\operatorname{Rogoff}(1996,1995)$ that allows for a welfare analysis that is better grounded than earlier more ad-hoc approaches.

The basic setup has been extended in several directions, with Engel (2001), Lane (2001) and Sarno (2001) providing recent surveys. One of the main avenue of research stresses the role played by the degree of substitutability between home and foreign goods (Corsetti and Pesenti (2000) and Tille (2001)). The central result is that when the goods produced by different countries are poor substitutes, a country suffers from an adverse 'beggarthyself' welfare effect when its currency depreciates, as the main impact is a worsening of the terms of trade. The limited degree of substitutability between goods produced in different countries is a central feature of several papers exploring a host of issues in international macroeconomics. ${ }^{1}$

All these contributions are however built on a restrictive assumption regarding the structure of the world economy, namely that there is complete sectoral specialization among countries. Under the usual Dixit-Stiglitz specification of preferences, consumers allocate their purchases first across types of goods that are poor substitutes (textiles and cars for instance), and then across highly substitutable brands for each type. Under the prevalent assumption of complete sectoral specialization, a particular type is produced only in one country. This specification has two significant drawbacks. First it implies that international trade is purely intersectoral, in the sense that each country exports a given type and imports other types. This is not consistent with the stylized fact that a substantial share of trade consists of intraindustry trade, where a country exports some brands of a given type while importing other brands of the same type (Grubel and Lloyd (1975)). Second, it abstracts from any inter-sectoral issues within countries. This omission is significant as several empirical studies have stressed the sectoral heterogene-

\footnotetext{
${ }^{1}$ See for instance Benigno and Benigno (2000), Chari, Kehoe and McGrattan (2000), Corsetti and Pesenti (2001), Devereux and Engel (2000), Devereux, Engel and Tille (1999), Obstfeld and Rogoff (2000a,b).
} 
ity of the impact of exchange rate fluctuations (Goldberg and Campa (2000), Goldberg and Tracy (2001), Gourinchas(1998)).

This paper addresses this shortcoming by building a more general setup that does not impose complete sectoral specialization, and let all countries produce all types of goods. The degree of sectoral specialization falls in an interval between the case with no specialization, where the production structure is the same in all countries, and the case with complete specialization. ${ }^{2}$ Note that we maintain the usual assumption of complete specialization at the brand level, as each brand is produced only by one firm. Therefore, a country exports some brands of each type while importing other brands of the same type, but no brand is simultaneously produced in different countries. Furthermore the degree of specialization is assumed exogenously, and is not the endogenous consequence of different factor endowments as is the case in trade models.

The emphasis of the analysis is on the distributional effects of exchange rate fluctuations. Each household specializes in the production of a brand, and asset markets are incomplete. This leads to a segmentation of households in a country according to the type of good they produce (textile makers and car makers). We show that exchange rate fluctuations have sharply different consequences for different households, as it affects their price competitiveness in an heterogenous way. The households who compete mostly against foreign [domestic] producers benefit from a large [negligible] gain in competitiveness following a depreciation. This heterogeneity carries through to the welfare results. In particular, whereas the adverse 'beggar-thyself' effect of a depreciation stressed by Tille (2001) remains valid for the country as a whole, it is concentrated on a majority of households while a minority actually benefits.

The paper is organized as follows. The model is presented in section 2. Section 3 discusses the impact of an exchange rate depreciation, both in positive and normative terms. The results are illustrated by a numerical example in section 4 , and section 5 concludes. We focus on the main results and the detailed steps are presented in the Appendix.

\footnotetext{
${ }^{2}$ The model compares to Faruqee (1996).
} 


\section{The model}

\subsection{Geographic and production structure}

The world is made of two countries, home and foreign. There is a continuum of consumer - producer households uniformly distributed along a unit interval. For simplicity we consider that both countries have the same size: households on the $[0,1 / 2)$ interval are residents of the home country, whereas households on the $[1 / 2,1]$ interval live in the foreign country.

Two types of goods are available for consumption, denoted by $A$ and $B$ (textiles and cars for example). Each type consists of a continuum of brands. The model is characterized by monopolistic competition, as each household is the sole producer of a particular brand. For simplicity we consider that the mass of brands, equal to the mass of households, is evenly distributed across good types, so that each type consists of a mass $1 / 2$ of brands. The central feature of this paper is to allow for a general production structure by not restricting each country to produce brands of only one type. Instead different brands from both types can be produced in both countries. More specifically we introduce a parameter $\gamma \in[0.5,1]$, referred to as the degree of sectoral specialization. Without loss of generality we assume that the home country specializes to some extent in producing type $A$. In the home country, households located on the $[0,0.5 \gamma)$ interval produce brands of type $A$, whereas households located on the $[0.5 \gamma, 0.5)$ interval produce brands of type $B$. Turning to the foreign country, households located on the $[0.5,0.5(2-\gamma))$ interval produce brands of type $A$, while households located on the $[0.5(2-\gamma), 1]$ interval produce brands of type $B$. The allocation is summarized in Table 1:

\begin{tabular}{|c|c|c|c|}
\hline \multicolumn{4}{|c|}{ Table 1: Production structure } \\
\hline Range & Country & $\begin{array}{c}\text { Type } \\
\text { produced }\end{array}$ & Mass \\
\hline \hline $0-0.5 \gamma$ & Home & $A$ & $0.5 \gamma$ \\
\hline $0.5 \gamma-0.5$ & Home & $B$ & $0.5(1-\gamma)$ \\
\hline $0.5-0.5(2-\gamma)$ & Foreign & $A$ & $0.5(1-\gamma)$ \\
\hline $0.5(2-\gamma)-1$ & Foreign & $B$ & $0.5 \gamma$ \\
\hline
\end{tabular}

Our setup implies that a fraction $\gamma \in[0.5,1]$ of households in the home country produce brands of type $A$, and the same fraction of foreign households produce brands of type $B$. Figure 1 illustrates various cases, with 
the left [right] squares representing the mass of households in the home [foreign] country. The top panel illustrates the situation under complete sectoral specialization $(\gamma=1)$ where each country produces only one type. In the middle panel, sectoral specialization is partial $(0.5<\gamma<1)$ : most, but not all, home households produce brands of type $A$, the situation being mirrored in the foreign country. Finally the bottom panel shows the case where there is no sectoral specialization $(\gamma=0.5)$ and the production structure is the same in both countries.

\subsection{Intratemporal consumption allocation}

The objective of a home household indexed by $g$, at time $t$ is to maximize her intertemporal utility:

$$
U_{t}^{g}=\sum_{s=0}^{\infty} \beta^{s}\left\{\ln \left(C_{t+s}^{g}\right)-\frac{\kappa}{2}\left(Y_{t+s}^{g}\right)^{2}+\chi \ln \left(\frac{M_{t+s}^{g}}{P_{t+s}}\right)\right\}
$$

where $\beta \in(0,1)$ is the discount rate, and $\chi, \kappa$ are positive scaling parameters. The first term is the utility of consumption, where $C^{g}$ is a consumption basket defined below. The second term represents the cost of effort, $Y^{g}$ being the output produced by the household. The last term captures the utility from liquidity services, where $M^{g}$ are the nominal balances and $P$ the consumer price index. The functional form in (1) is fairly specific and is chosen in order to keep the complexity of the analysis to a minimum.

The overall consumption basket, $C^{g}$, is a CES aggregate of the two available types of goods $A$ and $B$ :

$$
C^{g}=\left[\left(\frac{1}{2}\right)^{\frac{1}{\rho}}\left(C^{g}(A)\right)^{\frac{\rho-1}{\rho}}+\left(\frac{1}{2}\right)^{\frac{1}{\rho}}\left(C^{g}(B)\right)^{\frac{\rho-1}{\rho}}\right]^{\frac{\rho}{\rho-1}}
$$

where $C^{g}(A)$ and $C^{g}(B)$ are subindexes of the consumption of goods of type $A$ and type $B$ respectively. $\rho \geq 1$ is the elasticity of substitution between types. ${ }^{3}$ Each subindex is in turn a CES aggregate across the available brands. Brands produced in the home country are indexed by $z^{H}$, and brands produced in the foreign country are indexed by $z^{F}$. The subindexes are:

$C^{g}(A)=\left[2^{\frac{1}{\theta}} \int_{0}^{0.5 \gamma}\left(C^{g}\left(A, z^{H}\right)\right)^{\frac{\theta-1}{\theta}} d z^{H}+2^{\frac{1}{\theta}} \int_{0.5}^{0.5(2-\gamma)}\left(C^{g}\left(A, z^{F}\right)\right)^{\frac{\theta-1}{\theta}} d z^{F}\right]^{\frac{\theta}{\theta-1}}$

\footnotetext{
${ }^{3}$ For simplicity, we abstract from the cases where $0<\rho<1$.
} 
$C^{g}(B)=\left[2^{\frac{1}{\theta}} \int_{0.5 \gamma}^{0.5}\left(C^{g}\left(B, z^{H}\right)\right)^{\frac{\theta-1}{\theta}} d z^{H}+2^{\frac{1}{\theta}} \int_{0.5(2-\gamma)}^{1}\left(C^{g}\left(B, z^{F}\right)\right)^{\frac{\theta-1}{\theta}} d z^{F}\right]^{\frac{\theta}{\theta-1}}$

$C^{g}(A, z)$ and $C^{g}(B, z)$ denote the consumption of a particular brand $z\left(z^{H}\right.$ or $z^{F}$ ) of type $A$ and $B$ respectively. $\theta>1$ is the elasticity of substitution between two brands of the same type.

A central feature of the model is that there is more substitutability between brands of a given type than between types, that is: $1 \leq \rho \leq \theta$.

The intratemporal allocation of consumption across brands is derived in the usual way and the results are presented in Table 2. The home currency prices faced by a home consumer are defined as follows: $P^{A}(z)$ and $P^{B}(z)$ are the prices of a brand $z\left(z^{H}\right.$ or $\left.z^{F}\right)$ of type $A$ and $B$, respectively, $P^{A}$ and $P^{B}$ are the price indexes of type $A$ and $B$, respectively, and $P$ is the consumer price index. Variables for the foreign country are denoted by asterisks and are defined in a way similar to their counterparts for the home country.

\begin{tabular}{|c|c|}
\hline \multicolumn{3}{|c|}{ Table 2: Consumption allocation } \\
\hline$C^{g}(A, z)=\left[\frac{P^{A}(z)}{P^{A}}\right]^{-\theta}\left[\frac{P^{A}}{P}\right]^{-\rho} C^{g}$ & $C^{g}(B, z)=\left[\frac{P^{B}(z)}{P^{B}}\right]^{-\theta}\left[\frac{P^{B}}{P}\right]^{-\rho} C^{g}$ \\
$C^{g *}(A, z)=\left[\frac{P^{A *}(z)}{P^{A *}}\right]^{-\theta}\left[\frac{P^{A *}}{P^{*}}\right]^{-\rho} C^{g *}$ & $C^{g *}(B, z)=\left[\frac{P^{B *}(z)}{P^{B *}}\right]^{-\theta}\left[\frac{P^{B *}}{P^{*}}\right]^{-\rho} C^{g *}$ \\
\hline
\end{tabular}

The price indexes in the home country are presented in Table 3, and represent the minimum expenditure required to purchase one unit of the corresponding basket.

$$
\begin{aligned}
\text { Table 3: Price indexes } \\
\hline P^{A}=\left[2 \int_{0}^{0.5 \gamma}\left(P^{A}\left(z^{H}\right)^{1-\theta} d z^{H}+2 \int_{0.5}^{0.5(2-\gamma)}\left(P^{A}\left(z^{F}\right)\right)^{1-\theta} d z^{F}\right]^{\frac{1}{1-\theta}}\right. \\
P^{B}=\left[2 \int_{0.5 \gamma}^{0.5}\left(P^{B}\left(z^{H}\right)\right)^{1-\theta} d z^{H}+2 \int_{0.5(2-\gamma)}^{1}\left(P^{B}\left(z^{F}\right)\right)^{1-\theta} d z^{F}\right]^{\frac{1}{1-\theta}} \\
P=\left[\frac{1}{2}\left(P^{A}\right)^{1-\rho}+\frac{1}{2}\left(P^{B}\right)^{1-\rho}\right]^{\frac{1}{1-\rho}}
\end{aligned}
$$

Throughout the paper we assume that the law of one price holds: $P^{g}(z)=$ $S P^{* g}(z)$, where $g=A, B$ and $S$ is the nominal exchange rate defined as the number of unit of home currency per unit of foreign currency. As all goods are traded, the law of one price then also holds: $P=S P^{*}$. 


\subsection{Intertemporal optimization}

Having derived the intra-temporal allocation of consumption, we now turn to the budget constraint. Each household can hold two assets: domestic money and a nominal bond denominated in home currency. Financial markets are therefore incomplete both across and within countries, as households cannot trade contingent claims. Whereas the assumption of incomplete markets across countries is standard, the incompleteness of markets within countries can appear more disputable. We concede that is too extreme, as in reality households hold shares in firms other than the one they work in. Such a sectoral portfolio diversification is however limited. Furthermore, the assumption of incomplete markets within countries provides a useful benchmark as it allows us to analyze the heterogenous effects of monetary shocks in a tractable way.

We denote bond holdings at the beginning of period $t$ by $B_{t}^{g}$ and the interest rate paid over period $t$ by $i_{t}$. The budget constraint is then:

$$
\frac{B_{t+1}^{g}}{P_{t}}+\frac{M_{t}^{g}}{P_{t}}+C_{t}^{g}=\left(1+i_{t}\right) \frac{B_{t}^{g}}{P_{t}}+\frac{M_{t-1}^{g}}{P_{t}}+\frac{P_{t}^{g}\left(z^{H}\right)}{P_{t}} Y_{t}^{g}-T_{t}^{g}
$$

where $P_{t}^{g}\left(z^{H}\right)$ is the price charged by the household for the particular brand she produces. $T^{g}$ is a lump sum tax. The optimal choice for household $g$ is given by:

$$
\begin{aligned}
C_{t+1}^{g} & =\beta\left(1+i_{t+1}\right) \frac{P_{t}}{P_{t+1}} C_{t}^{g} \\
\frac{M_{t}^{g}}{P_{t}} & =\chi C_{t}^{g} \frac{1+i_{t+1}}{i_{t+1}}
\end{aligned}
$$

(3) is the Euler condition reflecting the optimal intertemporal allocation of consumption and (4) is the money demand. For simplicity we assume that there are no government spending and each household is repaid its seignorage tax as a lump-sum transfer: $M_{t}^{g}-M_{t-1}^{g}=P_{t} T_{t}^{g}$. Similar conditions can be derived for a foreign household:

$$
\begin{aligned}
C_{t+1}^{g *} & =\beta\left(1+i_{t}\right) \frac{S_{t} P_{t}^{*}}{S_{t+1} P_{t+1}^{*}} C_{t}^{g *} \\
\frac{M_{t}^{g *}}{P_{t}^{*}} & =\chi C_{t}^{g *} \frac{\left(1+i_{t}\right) S_{t+1}}{\left(1+i_{t}\right) S_{t+1}-S_{t}}
\end{aligned}
$$




\subsection{Production}

The demand faced by a specific household for the brand she produces is obtained by aggregating the results of table 2 across all households worldwide, using the law of one price:

$$
\begin{aligned}
Y^{g} & =\left[\frac{P^{g}\left(z^{H}\right)}{P^{g}}\right]^{-\theta}\left[\frac{P^{g}}{P}\right]^{-\rho} C^{w} \\
Y^{g *} & =\left[\frac{P^{g *}\left(z^{F}\right)}{P^{g *}}\right]^{-\theta}\left[\frac{P^{g *}}{P^{*}}\right]^{-\rho} C^{w}
\end{aligned}
$$

where $C^{w}=\int_{0}^{0.5} C^{k} d k+\int_{0.5}^{1} C^{k *} d k$ is the worldwide consumption. The optimal price setting in a flexible price framework leads to the usual result that households use their monopoly power and charge a markup over the marginal cost of effort:

$$
\begin{aligned}
P^{g}\left(z^{H}\right) & =P \frac{\theta \kappa}{\theta-1} C^{g} Y^{g} \\
P^{g *}\left(z^{F}\right) & =P^{*} \frac{\theta \kappa}{\theta-1} C^{g *} Y^{g *}
\end{aligned}
$$

It is important to realize that (9)-(10) do not necessarily hold. As detailed below, prices do not react immediately following a shock and output is then determined by the demands (7)-(8).

\section{The impact of exchange rate fluctuations}

\subsection{Methodology}

Our model being nonlinear, we first derive the solution for a symmetric steady state, and then analyze the model in terms of percentage deviations around it. In the symmetric steady state, no household has any net claims on other households: $B^{g}=B^{g *}=0$, the interest rate reflects the discount factor, and is equal to $\beta^{-1}-1$. All households worldwide are identical and each consumes and produces an amount $C_{0}=\sqrt{(\theta-1) /(\theta \kappa)}$, given by the optimal price setting (9)-(10). This level of output is suboptimally low because of monopolistic competition, with the marginal utility of consumption exceeding the marginal cost of production. 
The analysis is undertaken in terms of log linear approximations around the symmetric steady state, and lowercase letters denote percentage deviations from the symmetric steady state: $x=\left(X-X_{0}\right) / X_{0}$. The only exception is bond holdings, which are scaled by nominal consumption: $b^{g}=$ $B^{g} /\left(P_{0} C_{0}\right)$.

The economy is initially at the symmetric steady state. At time $t$, it is affected by a permanent monetary shock $\left(m_{t+s}=\bar{m}, m_{t+j}^{*}=\bar{m}^{*} \forall j \geq 0\right)$. We focus on monetary shocks as they play a non-negligible role in the short run exchange rate volatility (Rogers (1997)). The economy is characterized by nominal rigidities, as prices cannot instantaneously adjust to a shock. Instead, we consider that prices are set for period $t$ (the short run), and can be adjusted only at period $t+1$. We assume that prices are set in the producer currency, and the fluctuations of the exchange rate are entirely pass-through to consumer prices. From period $t+1$ on, the economy is in a new steady state the we refer to as the long run. The long run values are denoted by an upper bar.

For each country, we define per capita variables as weighted averages across both types:

$$
x=\gamma x^{A}+(1-\gamma) x^{B} \quad, \quad x^{*}=(1-\gamma) x^{A *}+\gamma x^{B *}
$$

Worldwide variables are defined as weighted averages of the country per capita variables:

$$
x^{w}=\frac{1}{2} x+\frac{1}{2} x^{*}
$$

We also define worldwide type-specific variables as weighted averages across all households of a given type in both countries:

$$
x^{A w}=\gamma x^{A}+(1-\gamma) x^{A *} \quad, \quad x^{B w}=(1-\gamma) x^{B}+\gamma x^{B *}
$$

\subsection{An intuitive exposition of the main results}

Before deriving the detailed results, we describe the underlying intuition. The key mechanism can be understood by focusing on the short run effect of a monetary expansion in the home country. As usual, such an expansion leads to a depreciation of the home currency. As prices are set in the producer currency, the exchange rate depreciation is passed-through to import prices, increasing them in the home country and reducing them in the foreign country. 
By lowering the price of home produced goods relative to foreign produced ones, the depreciation of the home currency generates a competitiveness gain for home households vis-a-vis their foreign counterparts. The extent of this gain is however sharply different depending of which type of good the household produces. The central element is the nationality of the competitors. A home household of type $A$ faces competition mostly from other home households, as there are only a minority of foreign producers of type $A$. The competitive position of a home household is then little affected by the depreciation as it does not affect her relative price vis-a-vis the majority of her competitors. The situation is sharply different for a home household of type $B$, who faces mostly foreign competition. The depreciation of the home currency then hands her a significant competitiveness gain by reducing her price vis-a-vis most of her competitors.

As home households of type $B$ benefit from a larger competitiveness gain that home households of type $A$, their sales and revenues increase by more. The difference in revenues translate into differences in consumption and savings. Although the purchasing power of home households is reduced by imported inflation, this affects type $A$ and $B$ identically. In welfare terms, the difference in terms of consumption is only partially offset by higher effort. The home households of type $B$ benefit from a depreciation by more than their counterparts of type $A$, who may actually suffer in absolute terms.

\subsection{Positive analysis}

Having described the central intuition of the model, we now derive the positive results. The complete steps are presented in the Appendix, and we focus on the mains results and their interpretation. Without loss of generality, we consider a monetary expansion in the home country $(\bar{m}>$ $\left.0, \bar{m}-\bar{m}^{*}>0\right)$. This expansion leads the exchange rate to immediately depreciate and then remain constant:

$$
s=\bar{s}=D^{-1}\left[1+\frac{2 \theta}{1+\theta} \frac{\beta}{1-\beta}\right]\left(\bar{m}-\bar{m}^{*}\right)
$$

where $D>0$ and $\partial s / \partial \gamma>0$ as $\partial D / \partial \gamma<0$. The sensitivity of the exchange rate to monetary shocks is higher the higher the degree of specialization $\gamma$. Intuitively each country produces a basket that is made of goods of both types, albeit to different extents. If the degree of specialization is moderate 
( $\gamma$ is close to 0.5 ), the home and foreign baskets are close substitutes, and only a moderate depreciation of the exchange rate is needed for the economy to adjust to the asymmetric monetary shock. By contrast if the degree of specialization is high ( $\gamma$ is close to 1 ), the two baskets are poor substitutes and it takes a large depreciation of the exchange rate for the economy to adjust.

As prices are set in the producer's currency, the depreciation affects the consumer prices of imports, increasing them in the home country and lowering them in the foreign country. The relative price between types is also affected. As the home country specializes in brands of type $A$, the home currency price index of type $A$ increases only moderately. The home currency price index for type $B$ increases by more, with most brands being imported. The relative price of type $A$ is then reduced:

$$
p^{A}-p^{B}=-(2 \gamma-1) s
$$

This relative price change leads to a worldwide consumption switching towards goods of type $A$ :

$$
y^{A w}-y^{B w}=\rho(2 \gamma-1) s
$$

where $y^{g w}$ is the average percentage change in output for households producing goods of type $g$, using the weighting (13). The consumption switching towards type $A$ remains moderate because of the limited substitutability between the types.

By making home produced goods more competitive, the depreciation increases the demand for such goods and leads to an output boom in the home country:

$$
y-y^{*}=\xi s=\left\{\theta\left[1-(2 \gamma-1)^{2}\right]+\rho(2 \gamma-1)^{2}\right\} s
$$

The elasticity of the cross-country output difference with respect to the depreciation, $\xi>0$, is a combination of the substitutability between types of goods, $\rho$, and between brands of a given type, $\theta$, with the weights reflecting the degree of specialization, $\gamma$. If there is little specialization $(\gamma$ is close to $0.5)$, the elasticity is close to the elasticity of substitution between brands, $\theta$. The home and foreign baskets are similar, and they are as substitutable as brands of a given type. The cross-country output difference is then very sensitive to the exchange rate. By contrast, is the degree of specialization is high ( $\gamma$ is close to 1$)$, the elasticity $\xi$ is close to the elasticity of substitution 
between types of goods, $\rho$. The home and foreign baskets are poor substitutes, and the cross-country output difference is less affected by the exchange rate. (14) shows that the weights on $\theta$ and $\rho$ are non-linear functions of the degree of specialization, with the weight on $\rho$ remaining small for low values of $\gamma$ and increasing significantly only for a high degree of specialization. ${ }^{4}$

Following steps outlined in the Appendix, we compute the solution for the cross-country consumption difference and the current account as follows:

$$
\begin{aligned}
c-c^{*} & =\frac{1}{1+\frac{2 \theta}{1+\theta} \frac{\beta}{1-\beta}}\left[+\frac{\theta-\rho}{\theta} \frac{2 \theta}{1+\theta} \frac{(\xi-1)}{(1-\beta)+\rho(1+\beta)}(2 \gamma-1)^{2}\right] s \\
b-b^{*} & =\frac{\frac{2 \theta}{1+\theta} \frac{\beta}{1-\beta}}{1+\frac{2 \theta}{1+\theta} \frac{\beta}{1-\beta}}\left[+(\rho-1)\left[1-\frac{\theta-\rho}{\theta} \frac{(1-\beta)}{(1-\beta)+\rho(1+\beta)}(2 \gamma-1)^{2}\right]\right] s
\end{aligned}
$$

The depreciation of the home currency generates an increase in consumption in the home country. Intuitively the income from the export boom, $y-y^{*}$, is large enough to offset the loss of purchasing power stemming from the worsening of the terms of trade. The additional income is spent partly on additional consumption, $c-c^{*}$, and partly on savings, $b-b^{*}$. The Appendix shows that the current account surplus leads home households to increase their consumption and reduce their effort in the long run.

The analysis in terms of cross-country differences is informative on the situation on the average home household, relative to the average foreign household. It does not however shed light on any discrepancies across households in a given country. This analysis is undertaken in the Appendix, and we can show that the output boom is smaller for the households who produce the type that the home country specializes in (type $A$ ):

$$
y^{A}-y^{B}=-(\theta-\rho)(2 \gamma-1) s
$$

As $\theta>\rho$ a depreciation implies that $y^{A}<y^{B}$. This reflects the differences in the nature of the competition faced by different households. Recall the demand faced by a home household producing brand $z^{H}$ of type $g$ :

$$
y^{g}=c^{w}-\theta\left[p^{g}\left(z^{H}\right)-p^{g}\right]-\rho\left(p^{g}-p\right)
$$

Three factors affect the demand. The first, $c^{w}$, reflects the strength of worldwide consumption and affects the demand for all brands identically. The

\footnotetext{
${ }^{4}$ Furthermore, the elasticity $\xi$ is larger in the long run than in the short run, as shown in the Appendix.
} 
second, $p^{g}-p$, is the change in the relative price across types. As already pointed, a depreciation lowers the price index of type $A$ relative to the price index of type $B$, so that: $p^{A}-p<0$ and $p^{B}-p>0$. The impact on the output demand is however limited as the elasticity of substitution between types, $\rho$, is small. The last aspect is the competitiveness gain vis-a-vis other producers of the same type, as captured by the relative price of the brand, $p^{g}\left(z^{H}\right)-p^{g}$. This is the most important factor as any change in relative prices is magnified by the high substitutability between brands, $\theta$. In the short run we can write:

$$
p^{A}\left(z^{H}\right)-p^{A}=-p^{A}=-(1-\gamma) s \quad, \quad p^{B}\left(z^{H}\right)-p^{B}=-p^{B}=-\gamma s
$$

As $\gamma \geq 0.5$ the competitiveness gain is smaller for home households of type $A$. Intuitively a home household of type $A$ faces competitors that are mostly from the home country, vis-a-vis whom she gains no competitiveness. By contrast a home household of type $B$ faces mostly foreign competitors and benefits from a substantial gain in competitiveness from the depreciation.

The stronger demand boost for home households of type $B$ in turns generates larger consumption and savings gains, relative to home households of type $A$ :

$$
\begin{aligned}
c^{A}-c^{B} & =-(\theta-\rho) \frac{1-\frac{2}{1+\theta} \frac{\beta(\rho-1)}{(1+\rho)+\beta(\rho-1)}}{1+\frac{2 \theta}{1+\theta} \frac{\beta}{1-\beta}}(2 \gamma-1) s \\
b^{A}-b^{B} & =-(\theta-\rho) \frac{2 \beta}{1+\theta} \frac{\frac{\theta}{1-\beta}+\frac{\rho-1}{(1+\rho)+\beta(\rho-1)}}{1+\frac{2 \theta}{1+\theta} \frac{\beta}{1-\beta}}(2 \gamma-1) s
\end{aligned}
$$

The smaller asset accumulation by households of type $A\left(b^{A}-b^{B}<0\right)$ in turns implies that they consume less and work more in the long run: $\bar{c}^{A}-\bar{c}^{B}<0, \bar{y}^{A}-\bar{y}^{B}<0$. Note that a depreciation limits the increase in consumption because it reduces the home households' purchasing power by increasing import prices. This aspect does not affect the situation of home households of type $A$ relative to home households of type $B$ however. As all households are faced with the same consumer prices, the depreciation equally reduces the purchasing power of all home households.

We can undertake a similar analysis for the foreign country, and find that output decreases more for foreign households of type $A$ :

$$
y^{A *}-y^{B *}=y^{A}-y^{B}=-(\theta-\rho)(2 \gamma-1) s
$$


The demand faced by a foreign household producing brand $z^{F}$ of type $g$ is given by:

$$
y^{g *}=c^{w}-\theta\left[p^{g *}\left(z^{F}\right)+s-p^{g}\right]-\rho\left(p^{g}-p\right)
$$

The main factor driving the demand is the competitiveness of the particular brand produced by the household, $p^{g *}\left(z^{F}\right)+s-p^{g}$. In the short run, we write:

$$
p^{A *}\left(z^{F}\right)+s-p^{A}=\gamma s \quad, \quad p^{B *}\left(z^{F}\right)+s-p^{B}=(1-\gamma) s
$$

The loss of competitiveness is larger for a foreign household of type $A$ because she competes mostly against home households whose goods are made more competitive by the depreciation. By contrast a foreign household of type $B$ compete mostly against other foreign households, against whom she looses no competitiveness. In terms of consumption and savings differentials in the foreign country, we can show that: $c^{A *}-c^{B *}=c^{A}-c^{B}, b^{A *}-b^{B *}=b^{A}-b^{B}$.

\subsection{Welfare analysis}

Our setup provides us with a well grounded welfare analysis of monetary shocks in the form of the household utility (1). Following the standard approach in the literature, we abstract from the direct welfare impact of real balances and focus on consumption and effort. The welfare of a home household of type $g$ is linearized as:

$$
u^{g}=c^{g}-\frac{\theta-1}{\theta} y^{g}+\frac{\beta}{1-\beta}\left[\bar{c}^{g}-\frac{\theta-1}{\theta} \bar{y}^{g}\right]
$$

with a similar expression for a foreign household. In worldwide terms, we get the standard result that a monetary expansion is beneficial as it temporarily brings output and consumption closer to the first best outcome: $u^{w}=\theta^{-1} \bar{m}^{w}>0$.

Following steps presented in the Appendix, we find that a depreciation of the home currency adversely affects home households, relative to their foreign counterparts:

$$
\begin{aligned}
u-u^{*} & =-\frac{\theta-\xi}{\theta} \frac{1+\rho}{(1-\beta)+\rho(1+\beta)} s \\
& =-\frac{\theta-\rho}{\theta} \frac{1+\rho}{(1-\beta)+\rho(1+\beta)}(2 \gamma-1)^{2} s
\end{aligned}
$$


The intuition for this 'beggar-thyself' is identical to Tille (2001), which is the case with $(2 \gamma-1)^{2}=1$. As long as the home country specializes in the production of type $A$ to some extent $(\gamma>0.5)$, the degree of substitutability between the home and the foreign baskets, $\xi$, is smaller that the degree of substitutability between two brands of a given basket, $\theta$. The limited substitutability between the home and foreign baskets implies that the depreciation leads only to a moderate boost in relative output, $y-y^{*}$, with a correspondingly small increase in sales revenue. The increase in relative home consumption, $c-c^{*}$, is further dampened by a limited ability for home households to substitute away from more expensive imports. The gain in home consumption, if any, brought by the depreciation of the home currency are then too small to offset the higher effort require to meet the increase in output, so that the home country looses relative to the foreign country $\left(u-u^{*}<0\right)$.

The adverse effect for the average home household hides significant differences across households. The difference in the home country can be derived as:

$$
u^{A}-u^{B}=-\frac{\theta-\rho}{\theta} \frac{1+\rho}{(1-\beta)+\rho(1+\beta)}(2 \gamma-1) s
$$

Home households of type $B$ benefit from a depreciation of the home currency, compared to home households of type $A$. They enjoy a higher increase in consumption that is only partially offset by a higher increase in effort.

Turning to foreign firms, we can show that the welfare effect is identical for households of a given type in both countries:

$$
u^{A *}=u^{A} \quad, \quad u^{B}=u^{B *}
$$

Our analysis shows that the average effect for a country is not representative, as the situation of sharply differs across households. For instance households of type $B$ always benefit from a depreciation of the home currency. Recalling that a depreciation stemming from a monetary expansion increases worldwide welfare $\left(u^{w}>0\right)$, the cross country results implies that the foreign country benefits $\left(u^{*}>0\right)$, a benefit that is concentrated amongst households of type $B\left(u^{B *}=u^{B}>0\right)$. By contrast households of type $A$ loose in relative terms $\left(u^{A}<u^{B}\right)$, and possibly in absolute terms $\left(u^{A}<0\right)$. Intuitively the loss for the home country is concentrated on the majority of households that face little foreign competition, whereas the minority of households in the sector that is foreign dominated $(B)$ benefit from a sizable gain in competitiveness. 


\section{A numerical illustration}

We illustrate our theoretical results by means of a numerical example. We set $\theta=6$, implying a steady state markup of $20 \%$. We choose $\beta=0.94$, corresponding to a steady state real interest rate of $6 \%$. We consider four cases for the degree of sectoral specialization: no specialization $(, \gamma=0.5)$, average specialization $(\gamma=0.75)$, large but incomplete specialization $(\gamma=$ $0.95)$, complete specialization $(\gamma=1)$. We also consider two possible values for the degree of substitutability between types: a low substitutability case $(\rho=1)$ and a high substitutability case $(\rho=4) .{ }^{5}$ Without loss of generality, we consider a unit monetary shock in the home country $\left(\bar{m}=1, \bar{m}^{*}=0\right)$.

The positive results are presented in table 4 . In the absence of specialization $(\gamma=0.5)$ all households in both country are in an identical situation, no matter how substitutable types are. A higher degree of sectoral specialization $\gamma$ reduces the magnitude of the effects on output, with a smaller boost in the home country $(y)$ and a smaller contraction in the foreign country $\left(y^{*}\right)$. When country are more specialized, the home and foreign baskets are poorer substitutes and the change of relative prices brought by the depreciation does not lead to a substantial consumption switching effect. The impact is however sharply different across households, as a higher degree of sectoral specialization reduces the output effect for home households of type $A$ but increases it for home households of type $B$. The situation is mirrored in the foreign country where households of type $A$ suffer from a large loss of competitiveness when specialization is high.

The output changes lead to changes in sales revenue that translate into consumption and savings. As the depreciation increases the average revenue in the home country, home consumption increases by more than foreign consumption. The differential is reduced when the degree of specialization is high, because in such a case the depreciation only moderately increases home output and revenue. The pattern differs depending on the type of the household. In the home country households of type $B$ experience a larger consumption boost than their counterparts of type $A$. The situation is mirrored in the foreign country. The higher revenue for the home country translates into a current account surplus $(b>0)$. This surplus decreases when sectoral specialization is larger, because the home and foreign baskets

\footnotetext{
${ }^{5}$ Recall that the distinction between types and brands is irrelevant when there is as much substitutability between types as between brands $(\rho=\theta)$.
} 
are then poor substitutes and the depreciation of the home currency leads to a small consumption switching towards home goods. The pattern again differs across households, with a higher sectoral specialization reducing the savings for home households of type $A$, while increasing the savings of home households of type $B$.

Table 5 shows the welfare effects. The values can be interpreted as the percentage increase in short run consumption that would lead to the same welfare effect as the monetary shock. ${ }^{6}$ In the absence of sectoral specialization $(\gamma=0.5)$, the monetary expansion equally benefits all households no matter how substitutable types are. Note that this corresponds to the results in Obstfeld and Rogoff (1996). When there is some sectoral specialization, the home country is worse off relative to the foreign country, and in absolute terms when there is little substitutability between types. The effects are strikingly different across households. The loss in the home country is concentrated among the majority of households of type $A$, whereas the minority of households of type $B$ benefit. When types are poor substitutes for instance $(\rho=1)$, if 95 percent of home households produce type $A$, they loose the equivalent of 0.28 percent of consumption, whereas the minority of households of type $B$ gains the equivalent of 0.45 percent of consumption. The situation is mirrored in the foreign country where the gain for the majority of type $B$ households comes at a cost for the minority of type $A$ households.

\section{Conclusion}

This paper shows that the exchange rate fluctuations can generate significant inter-sectoral differences within a country. This aspect is ignored by earlier contribution as they assume complete international sectoral specialization. Our analysis indicates that such an assumption is too restrictive. Whereas the impact of exchange rate fluctuations on the average household is consistent with earlier models, it hides significant differences across households. The adverse 'beggar-thyself' effect of a depreciation is concentrated on a majority of households, whereas a minority benefits. This feature reflects the different impact of the depreciation on competitiveness. Households

\footnotetext{
${ }^{6}$ For instance $u=0.12$ indicates that a $1 \%$ permanent monetary expansion in the home country has the same benefit for the average home household than a $0.12 \%$ percent increase in short run consumption $c$.
} 
that face a mostly domestic competition gain little, whereas the minority of import competing household benefits from a sizable combativeness gain.

The central role played by competitiveness considerations in our analysis suggests a caveat. A limited pass-through of exchange rate fluctuations to consumer prices, as in Betts and Devereux (2000), would dampen the mechanism. ${ }^{7}$

The analysis opens several avenues for future research. First, the distributional dimension points to a political economy analysis. Second, the assumption of an exogenous degree of specialization should be relaxed to explore how exchange rate fluctuations affect the choice of sector by producers. Finally, the sectoral dimension of the model provides a setup for the analysis of the optimal monetary policy reaction to sectoral shocks.

\footnotetext{
${ }^{7}$ For a recent review of the role of limited pass-through see Engel (2001).
} 


\section{Appendix}

\subsection{Building blocks}

This section present the linearized equations that constitute the building blocks of the model. We start with the price indexes in table 3:

$$
\begin{aligned}
p^{A} & =\gamma p^{A}\left(z^{H}\right)+(1-\gamma)\left[p^{A *}\left(z^{F}\right)+s\right] \\
p^{B} & =(1-\gamma) p^{B}\left(z^{H}\right)+\gamma\left[p^{B *}\left(z^{F}\right)+s\right] \\
p & =\frac{1}{2} p^{A}+\frac{1}{2} p^{B}
\end{aligned}
$$

where $p^{A}\left(z^{H}\right)$ is the (log deviation of the) price, in home currency, charged by the home firm producing brand $z^{H}$ of type $A$. As all firms producing a

given type in a given country are identical, so are their prices. $p^{A *}\left(z^{F}\right)+s$ is the price, in home currency, paid by a home household for brand $z^{F}$ of type $A$ produced in the foreign country. The price consists of the price charged by the foreign firm in foreign currency, $p^{A *}\left(z^{F}\right)$, corrected for the exchange rate, $s . p^{A}$ is the price, in home currency, paid by a home household for the basket of goods of type $A$. As the law of one price holds, the prices in the foreign country are:

$$
\begin{aligned}
p^{A *} & =\gamma\left[p^{A}\left(z^{H}\right)-s\right]+(1-\gamma) p^{A *}\left(z^{F}\right) \\
p^{B *} & =(1-\gamma)\left[p^{B}\left(z^{H}\right)-s\right]+\gamma p^{B *}\left(z^{F}\right) \\
p^{*} & =\frac{1}{2} p^{A *}+\frac{1}{2} p^{B *}=p-s
\end{aligned}
$$

Turning to the output demand, we use (7)-(8) to write:

$$
\begin{aligned}
y^{g} & =c^{w}-\theta\left[p^{g}\left(z^{H}\right)-p^{g}\right]-\rho\left[p^{g}-p\right] \\
y^{g *} & =c^{w}-\theta\left[p^{g *}\left(z^{F}\right)+s-p^{g}\right]-\rho\left[p^{g}-p\right]
\end{aligned}
$$

where $g=A, B$. The optimal pricing conditions (9)-(10) are linearized as follows:

$$
\begin{aligned}
\bar{p}^{g}(z) & =\bar{p}+\bar{y}^{g}+\bar{c}^{g} \\
\bar{p}^{g *}(z) & =-s+\bar{p}+\bar{y}^{g *}+\bar{c}^{g *}
\end{aligned}
$$


where the upper bars denote long run values, as (20)-(21) do not necessarily hold only in the short run. The budget constraint of a home household (2) and its foreign equivalent are linearized as:

$$
\begin{aligned}
b_{t+1}^{g}+c_{t}^{g} & =\frac{1}{\beta} b_{t}^{g}+y_{t}^{g}+p_{t}^{g}\left(z^{H}\right)-p_{t} \\
b_{t+1}^{g *}+c_{t}^{g *} & =\frac{1}{\beta} b_{t}^{g *}+y_{t}^{g *}+p_{t}^{g *}\left(z^{F}\right)-p_{t}^{*}
\end{aligned}
$$

As the nominal is in zero net supply worldwide, we write:

$$
\gamma b_{t}^{A}+(1-\gamma) b_{t}^{B}+(1-\gamma) b_{t}^{A *}+\gamma b_{t}^{B *}=0
$$

The Euler equations (3), (5) and the money demands (4), (6) are linearized as:

$$
\begin{aligned}
c_{t+1}^{g} & =c_{t}^{g}+\beta d i_{t+1}-\left(p_{t+1}-p_{t}\right) \\
c_{t+1}^{g *} & =c_{t}^{g *}+\beta d i_{t+1}-\left(p_{t+1}-p_{t}\right) \\
m_{t}^{g}-p_{t} & =c_{t}^{g}-\frac{\beta}{1-\beta} \beta d i_{t+1} \\
m_{t}^{g *}-p_{t}^{*} & =c_{t}^{g *}-\frac{\beta}{1-\beta}\left(\beta d i_{t+1}+s_{t+1}-s_{t}\right)
\end{aligned}
$$

Combining these equations, we can show that the exchange immediately reaches its long run value following permanent monetary shocks:

$$
\begin{aligned}
c_{t+1}^{g}-c_{t}^{g} & =c_{t+1}^{g *}-c_{t}^{g *}=\beta d i_{t+1}-\left(p_{t+1}-p_{t}\right) \quad \forall g \\
m_{t}^{g}-p_{t} & =c_{t}^{g}-\frac{\beta}{1-\beta} \beta d i_{t+1} \\
m_{t}^{g *}-p_{t}^{*} & =c_{t}^{g *}-\frac{\beta}{1-\beta} \beta d i_{t+1}
\end{aligned}
$$

\subsection{Positive analysis}

\subsubsection{Worldwide aggregate results}

We start by computing the worldwide results. Using the aggregation rule for worldwide variables (12), we find that the worldwide real effects are limited to the short run:

$$
c^{w}=y^{w}=\bar{m}^{w} \quad, \quad \bar{c}^{w}=\bar{y}^{w}=0
$$




\subsubsection{Worldwide differences across types}

We then turn to the solution in terms of worldwide differences across types using the aggregation rules (13). In the long run, we use the price indexes (16)-(17), the output demands (18)-(19), the optimal pricing (20)(21) and the budget constraints (22)-(23) to write:

$$
\begin{aligned}
\bar{y}^{A w}-\bar{y}^{B w} & =-\rho\left(\bar{p}^{A}-\bar{p}^{B}\right) \\
\bar{p}^{A}-\bar{p}^{B} & =\left(\bar{y}^{A w}-\bar{y}^{B w}\right)+\left(\bar{c}^{A w}-\bar{c}^{B w}\right) \\
\bar{c}^{A w}-\bar{c}^{B w} & =\frac{1-\beta}{\beta}\left(b^{A w}-b^{B w}\right)+\left(\bar{y}^{A w}-\bar{y}^{B w}\right)+\left(\bar{p}^{A}-\bar{p}^{B}\right)
\end{aligned}
$$

The system is solved as:

$$
\begin{aligned}
\bar{c}^{A w}-\bar{c}^{B w} & =\frac{1+\rho}{2 \rho} \frac{1-\beta}{\beta}\left(b^{A w}-b^{B w}\right) \\
\bar{y}^{A w}-\bar{y}^{B w} & =-\frac{1}{2} \frac{1-\beta}{\beta}\left(b^{A w}-b^{B w}\right) \\
\bar{p}^{A}-\bar{p}^{B} & =\frac{1}{2 \rho} \frac{1-\beta}{\beta}\left(b^{A w}-b^{B w}\right)
\end{aligned}
$$

Turning to the short run, the Euler equations (24) imply that $c^{A w}-c^{B w}=$ $\bar{c}^{A w}-\bar{c}^{B w}$. Recall that in the short run prices are fixed: $p^{g}\left(z^{H}\right)=p^{g *}\left(z^{F}\right)=$ 0 . Combining the prices indexes (16)-(17), the output demands (18)-(19) and the budget constraints (22)-(23) we derive:

$$
\begin{aligned}
y^{A w}-y^{B w} & =-\rho\left(p^{A}-p^{B}\right)=\rho(2 \gamma-1) s \\
c^{A w}-c^{B w} & =-(2 \gamma-1) s+\left(y^{A w}-y^{B w}\right)-\left(b^{A w}-b^{B w}\right)
\end{aligned}
$$

Using the long run solution, we obtain:

$$
\begin{aligned}
& c^{A w}-c^{B w}=(1+\rho)(1-\beta) \frac{\rho-1}{(1-\beta)+\rho(1+\beta)}(2 \gamma-1) s \\
& b^{A w}-b^{B w}=2 \rho \beta \frac{\rho-1}{(1-\beta)+\rho(1+\beta)}(2 \gamma-1) s
\end{aligned}
$$

From which we write:

$$
\bar{p}^{A}-\bar{p}^{B}=\frac{(1-\beta)(\rho-1)}{(1-\beta)+\rho(1+\beta)}(2 \gamma-1) s
$$




\subsubsection{Cross-country differences}

The next step is to analyze the model in terms of cross country differences, using the aggregation rules (11). We start with the long run. From the output demands (18)-(19), we write:

$$
\begin{aligned}
\bar{y}-\bar{y}^{*}= & -\theta\left[\gamma \bar{p}^{A}\left(z^{H}\right)+(1-\gamma) \bar{p}^{B}\left(z^{H}\right)-(1-\gamma)\left[\bar{p}^{A *}\left(z^{F}\right)+s\right]-\gamma\left[\bar{p}^{B *}\left(z^{F}\right)+s\right]\right] \\
& +(\theta-\rho)(2 \gamma-1)\left(\bar{p}^{A}-\bar{p}^{B}\right) \\
= & -\theta \overline{t o t}+(\theta-\rho)(2 \gamma-1)\left(\bar{p}^{A}-\bar{p}^{B}\right)
\end{aligned}
$$

where $\overline{t o t}=\left[\gamma \bar{p}^{A}\left(z^{H}\right)+(1-\gamma) \bar{p}^{B}\left(z^{H}\right)\right]-\left[(1-\gamma) \bar{p}^{A *}\left(z^{F}\right)+\gamma \bar{p}^{B *}\left(z^{F}\right)+s\right]$ is the terms of trade. The optimal pricing (20)-(21) and the budget constraints (22)-(23) are written as:

$$
\begin{aligned}
\bar{c}-\bar{c}^{*} & =\overline{t o t}+\left(\bar{y}-\bar{y}^{*}\right)+\frac{1-\beta}{\beta}\left(b-b^{*}\right) \\
\overline{t o t} & =\left(\bar{y}-\bar{y}^{*}\right)+\left(\bar{c}-\bar{c}^{*}\right)
\end{aligned}
$$

The system is then solved as:

$$
\begin{aligned}
\bar{c}-\bar{c}^{*} & =\frac{\theta-\rho}{\theta}(2 \gamma-1)\left(\bar{p}^{A}-\bar{p}^{B}\right)+\frac{1+\theta}{2 \theta} \frac{1-\beta}{\beta}\left(b-b^{*}\right) \\
\bar{y}-\bar{y}^{*} & =-\frac{1}{2} \frac{1-\beta}{\beta}\left(b-b^{*}\right) \\
\overline{t o t} & =\frac{\theta-\rho}{\theta}(2 \gamma-1)\left(\bar{p}^{A}-\bar{p}^{B}\right)+\frac{1}{2 \theta} \frac{1-\beta}{\beta}\left(b-b^{*}\right)
\end{aligned}
$$

Turning to the short run, the Euler (24) imply that $\bar{c}-\bar{c}^{*}=c-c^{*}$. The output demands (18)-(19) and budget constraints (22)-(23) are written as:

$$
\begin{aligned}
y-y^{*} & =\theta s+(\theta-\rho)(2 \gamma-1)\left(p^{A}-p^{B}\right)=\left[\theta-(\theta-\rho)(2 \gamma-1)^{2}\right] s \\
c-c^{*} & =-s+\left(y-y^{*}\right)-\left(b-b^{*}\right)
\end{aligned}
$$

Combining with the long run results, we derive:

$$
\left(c-c^{*}\right)\left[1+\frac{2 \theta}{1+\theta} \frac{\beta}{1-\beta}\right]=\left[\begin{array}{c}
(\theta-1)-(\theta-\rho)(2 \gamma-1)^{2} \\
+\frac{\theta-\rho}{\theta} \frac{2 \theta}{1+\theta} \frac{\beta(\rho-1)}{(1-\beta)+\rho(1+\beta)}(2 \gamma-1)^{2}
\end{array}\right] s
$$


The next step is to combine this results with the money demands (25)-(26): $\bar{m}-\bar{m}^{*}-s=c-c^{*}$, and obtain the cross-country solution:

$$
\begin{aligned}
& c-c^{*}=D^{-1}\left[\begin{array}{c}
(\theta-1)-(\theta-\rho)(2 \gamma-1)^{2} \\
+\frac{\theta-\rho}{\theta} \frac{2 \theta}{1+\theta} \frac{\beta(\rho-1)}{(1-\beta)+\rho(1+\beta)}(2 \gamma-1)^{2}
\end{array}\right]\left(\bar{m}-\bar{m}^{*}\right) \\
& s=D^{-1}\left[1+\frac{2 \theta}{1+\theta} \frac{\beta}{1-\beta}\right]\left(\bar{m}-\bar{m}^{*}\right) \\
& b-b^{*}=D^{-1} \frac{2 \theta}{1+\theta} \frac{\beta}{1-\beta}\left[\begin{array}{c}
\theta-1-(\theta-\rho)(2 \gamma-1)^{2} \\
-\frac{\theta-\rho}{\theta} \frac{(1-\beta)(\rho-1)}{(1-\beta)+\rho(1+\beta)}(2 \gamma-1)^{2}
\end{array}\right]\left(\bar{m}-\bar{m}^{*}\right)
\end{aligned}
$$

where:

$$
D=\theta+\frac{2 \theta}{1+\theta} \frac{\beta}{1-\beta}-(\theta-\rho)(2 \gamma-1)^{2}\left[1-\frac{2}{1+\theta} \frac{\beta(\rho-1)}{1+\rho+\beta(\rho-1)}\right]
$$

We can show that $D>0$. First, notice that the term in brackets is strictly positive. Therefore, recalling that $\theta \geq \rho \geq 1,2 \gamma \geq 1$, we write:

$$
\frac{\partial D}{\partial \gamma}=-4(\theta-\rho)(2 \gamma-1)\left[1-\frac{2}{1+\theta} \frac{\beta(\rho-1)}{(1-\beta)+\rho(1+\beta)}\right] \leq 0
$$

with a strict equality if $\theta=\rho$ or $2 \gamma=1$. Furthermore, we can show:

$$
D(\gamma=1)=\left\{\begin{array}{c}
\rho\left[1-\frac{2}{1+\theta} \frac{\beta(\rho-1)}{(1-\beta)+\rho(1+\beta)}\right] \\
+\frac{2 \theta}{1+\theta}\left[\frac{\beta}{1-\beta}+\frac{\beta(\rho-1)}{(1-\beta)+\rho(1+\beta)}\right]
\end{array}\right\}>0
$$

Therefore $D$ is a decreasing function of $\gamma$ when $\gamma \in[0.5,1]$ and $D>0$ when $\gamma=1$, which implies that $D>0$ for when $\gamma \in[0.5,1]$.

\subsubsection{Country specific cross-type differences}

We now turn to the difference across types within each country, starting with the home country. In the long run, we use the price indexes (16), the output demands (18), the optimal pricing (20) and the budget constraints (22) to write:

$$
\begin{aligned}
\bar{y}^{A}-\bar{y}^{B} & =-\theta\left[\bar{p}^{A}\left(z^{H}\right)-\bar{p}^{B}\left(z^{H}\right)\right]+(\theta-\rho)\left(\bar{p}^{A}-\bar{p}^{B}\right) \\
\bar{c}^{A}-\bar{c}^{B} & =\left[\bar{p}^{A}\left(z^{H}\right)-\bar{p}^{B}\left(z^{H}\right)\right]+\left(\bar{y}^{A}-\bar{y}^{B}\right)+\frac{1-\beta}{\beta}\left(b^{A}-b^{B}\right) \\
\bar{p}^{A}\left(z^{H}\right)-\bar{p}^{B}\left(z^{H}\right) & =\left(\bar{c}^{A}-\bar{c}^{B}\right)+\left(\bar{y}^{A}-\bar{y}^{B}\right)
\end{aligned}
$$


The system is solved as:

$$
\begin{aligned}
\bar{c}^{A}-\bar{c}^{B} & =\frac{\theta-\rho}{\theta}\left(\bar{p}^{A}-\bar{p}^{B}\right)+\frac{1+\theta}{2 \theta} \frac{1-\beta}{\beta}\left(b^{A}-b^{B}\right) \\
\bar{y}^{A}-\bar{y}^{B} & =-\frac{1}{2} \frac{1-\beta}{\beta}\left(b^{A}-b^{B}\right) \\
\bar{p}^{A}\left(z^{H}\right)-\bar{p}^{B}\left(z^{H}\right) & =\frac{\theta-\rho}{\theta}\left(\bar{p}^{A}-\bar{p}^{B}\right)+\frac{1}{2 \theta} \frac{1-\beta}{\beta}\left(b^{A}-b^{B}\right)
\end{aligned}
$$

Turning to the short run, the Euler equations (24) imply that $\bar{c}^{A}-\bar{c}^{B}=$ $c^{A}-c^{B}$. The output demands (18) and budget constraints (22) can be written as:

$$
\begin{aligned}
y^{A}-y^{B} & =(\theta-\rho)\left(p^{A}-p^{B}\right) \\
c^{A}-c^{B} & =\left(y^{A}-y^{B}\right)-\left(b^{A}-b^{B}\right)
\end{aligned}
$$

Combining this with the long run results and our solution for $\bar{p}^{A}-\bar{p}^{B}$ and $p^{A}-p^{B}$ leads to:

$$
\begin{aligned}
c^{A}-c^{B} & =-(\theta-\rho) \frac{1-\frac{2}{1+\theta} \frac{\beta(\rho-1)}{(1+\rho)+\beta(\rho-1)}}{1+\frac{2 \theta}{1+\theta} \frac{\beta}{1-\beta}}(2 \gamma-1) s \\
y^{A}-y^{B} & =-(\theta-\rho)(2 \gamma-1) s \\
b^{A}-b^{B} & =-(\theta-\rho) \frac{2 \beta}{1+\theta} \frac{\frac{\theta}{1-\beta}+\frac{\rho-1}{(1+\rho)+\beta(\rho-1)}}{1+\frac{2 \theta}{1+\theta} \frac{\beta}{1-\beta}}(2 \gamma-1) s
\end{aligned}
$$

Similar steps can be undertaken for the foreign country.

\subsubsection{Cross-country output differences and the terms of trade}

This section focuses on the elasticity of the cross-country output difference with respect to the terms of trade. This elasticity is defined as:

$\xi=-\frac{y-y^{*}}{t o t}=-\frac{y-y^{*}}{\left[\gamma p^{A}\left(z^{H}\right)+(1-\gamma) p^{B}\left(z^{H}\right)\right]-\left[(1-\gamma) p^{A *}\left(z^{F}\right)+\gamma p^{B *}\left(z^{F}\right)+s\right]}$

Using our short run results for the cross country output difference and the prices, we write the short run elasticity as:

$$
\xi=\theta\left[1-(2 \gamma-1)^{2}\right]+\rho(2 \gamma-1)^{2}
$$


Turning to the long run, recall that:

$$
\bar{y}-\bar{y}^{*}=-\theta \overline{t o t}+(\theta-\rho)(2 \gamma-1)\left(\bar{p}^{A}-\bar{p}^{B}\right)=-\frac{1}{2} \frac{1-\beta}{\beta}\left(b-b^{*}\right)
$$

Using the solution for $\bar{y}-\bar{y}^{*}$ and $\bar{p}^{A}-\bar{p}^{B}$, we write:

$$
\begin{aligned}
\bar{\xi} & =-\frac{\bar{y}-\bar{y}^{*}}{\overline{t o t}}=\frac{\theta\left(\bar{y}-\bar{y}^{*}\right)}{\left(\bar{y}-\bar{y}^{*}\right)-(\theta-\rho)(2 \gamma-1)\left(\bar{p}^{A}-\bar{p}^{B}\right)} \\
& =\frac{\theta \frac{1}{2} \frac{1-\beta}{\beta}\left(b-b^{*}\right)}{\frac{1}{2} \frac{1-\beta}{\beta}\left(b-b^{*}\right)+(\theta-\rho) \frac{(1-\beta)(\rho-1)}{(1-\beta)+\rho(1+\beta)}(2 \gamma-1)^{2} s}
\end{aligned}
$$

Using the solutions for $b-b^{*}$ and $s$, we obtain:

$\bar{\xi}=\theta \frac{\theta\left[\theta-1-(\theta-\rho)(2 \gamma-1)^{2}\left[1+\frac{1}{\theta} \frac{(1-\beta)(\rho-1)}{(1-\beta)+\rho(1+\beta)}\right]\right]}{(\theta-\rho)(\rho-1) \frac{(1-\beta)+\theta(1+\beta)}{(1-\beta)+\rho(1+\beta)}(2 \gamma-1)^{2}+\theta\left[\theta-1-(\theta-\rho)(2 \gamma-1)^{2}\left[1+\frac{1}{\theta} \frac{(1-\beta)(\rho-1)}{(1-\beta)+\rho(1+\beta)}\right]\right]}$

To analyze this elasticity, recall that $\beta$ is close to 1 , so that we can write:

$$
\bar{\xi} \simeq \rho \theta \frac{(\theta-1)-(\theta-\rho)(2 \gamma-1)^{2}}{(\theta-1) \rho-(\theta-\rho)(2 \gamma-1)^{2}}
$$

This implies that $\bar{\xi} \simeq \theta$ if $\gamma=0.5, \bar{\xi} \simeq \rho$ if $\gamma=1, \rho<\bar{\xi}<\theta$ if $0.5<\gamma<1$ (because $\rho \geq 1$ ). Furthermore we can show that the long run elasticity exceeds the short run elasticity $(\bar{\xi}>\xi)$ when $0.5<\gamma<1$.

A more detailed proof that $\rho \leq \xi \leq \bar{\xi} \leq \theta$ goes as follows. First notice that:

$$
\bar{\xi}(\gamma=0.5)=\theta \quad, \quad \bar{\xi}(\gamma=1)=\rho
$$

and recall that we already now that $\rho \leq \xi \leq \theta$. Next, consider the case of $\rho=1$. If $\gamma=1$, we have $\bar{\xi}=\xi=1$. If $\gamma<1$, we see that $\bar{\xi}=\theta \geq \xi$.

Turning to the case where $\rho>1$, we re-arrange the output demands (18)-(19) in the short and the long run:

$$
\begin{aligned}
\theta \overline{t o t} & =\frac{(1-\beta)(\rho-1)}{(1-\beta)+\rho(1+\beta)}(\theta-\rho)(2 \gamma-1)^{2} s-\left(\bar{y}-\bar{y}^{*}\right) \\
\theta t o t & =-(\theta-\rho)(2 \gamma-1)^{2} s-\left(y-y^{*}\right)
\end{aligned}
$$


Recalling that tot $<0$, and $\overline{t o t}>0$ (when $\rho>1$ ), we have:

$$
\begin{aligned}
& \bar{\xi}=\theta-\frac{(1-\beta)(\rho-1)}{(1-\beta)+\rho(1+\beta)}(\theta-\rho)(2 \gamma-1)^{2} \frac{s}{\overline{t o t}}<\theta \\
& \xi=\theta+(\theta-\rho)(2 \gamma-1)^{2} \frac{s}{t o t}<\theta
\end{aligned}
$$

Next, derive the condition under which the elasticity is stronger in the long run:

$$
\bar{\xi}>\xi \Leftrightarrow \frac{s}{\overline{t o t}}<\frac{(1-\beta)+\rho(1+\beta)}{(1-\beta)(\rho-1)}
$$

Using our results and some algebra, this condition is written as:

$$
\frac{(1-\beta)+\theta(1+\beta)}{(\theta-1)[(1-\beta)+\rho(1+\beta)]-2(\theta-\rho)(2 \gamma-1)^{2}}<\frac{1}{(\rho-1)}
$$

Now recall that $\beta$ is close to 1 , hence we can approximate the condition as follows:

$$
\begin{aligned}
\frac{\theta}{(\theta-1) \rho-(\theta-\rho)(2 \gamma-1)^{2}} & <\frac{1}{\rho-1} \Leftrightarrow-(\theta-\rho)<-(\theta-\rho)(2 \gamma-1)^{2} \\
& \Leftrightarrow 1>(2 \gamma-1)^{2}
\end{aligned}
$$

which is true for $\gamma<1$.

\subsection{Welfare analysis}

\subsubsection{Worldwide aggregate results}

The worldwide aggregate welfare effect is easily computed from a weighted average of the criterion (15) and the solution for consumption and effort. A monetary expansion is unambiguously beneficial:

$$
u^{w}=c^{w}-\frac{\theta-1}{\theta} y^{w}=\frac{1}{\theta} \bar{m}^{w}
$$

\subsubsection{Worldwide differences across types}

To compute the welfare effect across types, recall the output demands (18)-(19) and the budget constraints (22)-(23) in the short and the long run:

$$
\bar{c}^{A w}-\bar{c}^{B w}=\left(\bar{p}^{A}-\bar{p}^{B}\right)+\left(\bar{y}^{A w}-\bar{y}^{B w}\right)+\frac{1-\beta}{\beta}\left(b^{A w}-b^{B w}\right)
$$




$$
\begin{aligned}
\bar{y}^{A w}-\bar{y}^{B w} & =-\rho\left(\bar{p}^{A}-\bar{p}^{B}\right) \\
c^{A w}-c^{B w} & =-(2 \gamma-1) s+\left(y^{A w}-y^{B w}\right)-\left(b^{A w}-b^{B w}\right) \\
y^{A w}-y^{B w} & =\rho(2 \gamma-1) s
\end{aligned}
$$

We combine these relations with the linearized welfare criterion (15), along with our results for $\bar{p}^{A}-\bar{p}^{B}$ and write:

$$
\begin{aligned}
u^{A w}-u^{B w}= & -(1-\rho)(2 \gamma-1) s-\frac{\theta-1}{\theta} \rho(2 \gamma-1) s \\
& +\frac{\beta}{1-\beta}\left[(1-\rho)\left(\bar{p}^{A}-\bar{p}^{B}\right)+\frac{\theta-1}{\theta} \rho\left(\bar{p}^{A}-\bar{p}^{B}\right)\right] \\
= & -\frac{\theta-\rho}{\theta}(2 \gamma-1) s+\frac{\beta}{1-\beta} \frac{\theta-\rho}{\theta}\left(\bar{p}^{A}-\bar{p}^{B}\right) \\
= & -\frac{\theta-\rho}{\theta} \frac{1+\rho}{(1-\beta)+\rho(1+\beta)}(2 \gamma-1) s
\end{aligned}
$$

\subsubsection{Cross-country differences}

In terms of cross-country differences, the output demands (18)-(19) and the budget constraints (22)-(23) imply:

$$
\begin{aligned}
c-c^{*} & =-s+\left(y-y^{*}\right)-\left(b-b^{*}\right) \\
y-y^{*} & =\theta s-(\theta-\rho)(2 \gamma-1)^{2} s \\
\bar{c}-\bar{c}^{*} & =\overline{t o t}+\left(\bar{y}-\bar{y}^{*}\right)+\frac{1-\beta}{\beta}\left(b-b^{*}\right) \\
\bar{y}-\bar{y}^{*} & =-\theta \overline{t o t}+(\theta-\rho)(2 \gamma-1)\left(\bar{p}^{A}-\bar{p}^{B}\right)
\end{aligned}
$$

The cross-country welfare difference is then written as:

$$
\begin{aligned}
u-u^{*}= & -s+\theta s-(\theta-\rho)(2 \gamma-1)^{2} s-(\theta-1) s+\frac{\theta-1}{\theta}(\theta-\rho)(2 \gamma-1)^{2} s \\
& +\frac{\beta}{1-\beta}\left[\begin{array}{c}
\overline{t o t}-\theta \overline{t o t}+(\theta-\rho)(2 \gamma-1)\left(\bar{p}^{A}-\bar{p}^{B}\right)+(\theta-1) \overline{t o t} \\
-\frac{\theta-1}{\theta}(\theta-\rho)(2 \gamma-1)\left(\bar{p}^{A}-\bar{p}^{B}\right)
\end{array}\right] \\
= & -\frac{\theta-\rho}{\theta}(2 \gamma-1)^{2} s+\frac{\beta}{1-\beta} \frac{\theta-\rho}{\theta}(2 \gamma-1)\left(\bar{p}^{A}-\bar{p}^{B}\right) \\
= & -\frac{\theta-\rho}{\theta} \frac{1+\rho}{(1-\beta)+\rho(1+\beta)}(2 \gamma-1)^{2} s
\end{aligned}
$$




\subsubsection{Country specific cross-type differences}

In the home country, the output demands (18)-(19) and the budget constraints (22)-(23) imply that:

$$
\begin{aligned}
c^{A}-c^{B} & =\left(y^{A}-y^{B}\right)-\left(b^{A}-b^{B}\right) \\
y^{A}-y^{B} & =-(\theta-\rho)(2 \gamma-1) s \\
\bar{c}^{A}-\bar{c}^{B} & =\left[\bar{p}^{A}(z)-\bar{p}^{B}(z)\right]+\left(\bar{y}^{A}-\bar{y}^{B}\right)+\frac{1-\beta}{\beta}\left(b^{A}-b^{B}\right) \\
\bar{y}^{A}-\bar{y}^{B} & =-\theta\left[\bar{p}^{A}(z)-\bar{p}^{B}(z)\right]+(\theta-\rho)\left(\bar{p}^{A}-\bar{p}^{B}\right)
\end{aligned}
$$

The welfare difference is then written as:

$$
\begin{aligned}
u^{A}-u^{B}= & -(\theta-\rho)(2 \gamma-1) s+\frac{\theta-1}{\theta}(\theta-\rho)(2 \gamma-1) s \\
& +\frac{\beta}{1-\beta}\left[(\theta-\rho)\left(\bar{p}^{A}-\bar{p}^{B}\right)-\frac{\theta-1}{\theta}(\theta-\rho)\left(\bar{p}^{A}-\bar{p}^{B}\right)\right] \\
= & -\frac{\theta-\rho}{\theta}(2 \gamma-1) s+\frac{\beta}{1-\beta} \frac{\theta-\rho}{\theta}\left(\bar{p}^{A}-\bar{p}^{B}\right) \\
= & -\frac{\theta-\rho}{\theta} \frac{1+\rho}{(1-\beta)+\rho(1+\beta)}(2 \gamma-1) s
\end{aligned}
$$

Following similar steps, we can show that $u^{A *}-u^{B *}=u^{A}-u^{B}$. We can combine this result with the cross-country welfare difference as follows. From the aggregation rules, we know that:

$$
\begin{aligned}
u-u^{*} & =\gamma u^{A}+(1-\gamma) u^{B}-(1-\gamma) u^{A *}-\gamma u^{B *} \\
& =\gamma\left(u^{A}-u^{B}\right)+\gamma\left(u^{A *}-u^{B *}\right)+u^{B}-u^{A *}
\end{aligned}
$$

Therefore, we use our results to write:

$$
\begin{aligned}
u^{A *}-u^{B} & =2 \gamma\left(u^{A}-u^{B}\right)-\left(u-u^{*}\right) \\
& =[-2 \gamma+2 \gamma-1] \frac{\theta-\rho}{\theta} \frac{1+\rho}{(1-\beta)+\rho(1+\beta)}(2 \gamma-1) s \\
& =-\frac{\theta-\rho}{\theta} \frac{1+\rho}{(1-\beta)+\rho(1+\beta)}(2 \gamma-1) s \\
& =u^{A}-u^{B}
\end{aligned}
$$

Which implies that the absolute welfare effects are the same for a given type across countries:

$$
u^{A *}=u^{A}, u^{B}=u^{B *}
$$




\section{References}

[1] Benigno, Gianluca, and Pierpaolo Benigno, 2000, Monetary Policy rules and the Exchange Rate, CEPR Discussion Paper 2807.

[2] Betts, Caroline, and Michael Devereux, 2000, Exchange Rate Dynamics in a Model of Pricing-To-Market, Journal of International Economics 50, 215-244.

[3] Chari, V.V., Patrick Kehoe and Ellen McGrattan, 2000, Can Sticky Prices Models generate Volatile and Persistent Real Exchange Rates?, Federal Reserve bank of Minneapolis Staff Report 277.

[4] Corsetti, Giancarlo, and Paolo Pesenti, 2001, International Dimensions of Optimal Monetary Policy, NBER Working Paper 8230.

[5] Corsetti, Giancarlo, and Paolo Pesenti, 2000, Welfare and Macroeconomic Interdependence, Quarterly Journal of Economics 116, 421-446.

[6] Devereux, Michael, and Charles Engel, 2000, Monetary Policy in the Open Economy Revisited: Price Setting and Exchange Rate Flexibility, NBER Working Paper 7665.

[7] Devereux, Michael, Charles Engel and Cédric Tille, 1999, Exchange Rate Pass-Through and the Welfare Effects of the Euro, International Economic Review, forthcoming.

[8] Engel, Charles, 2001, The Responsiveness of Consumer Prices to Exchange Rates And the Implications for Exchange Rate Policy: A Survey of A Few Recent New Open Economy Macro Models, mimeo, University of Wisconsin.

[9] Faruqee, Hamid, 1996, Real Exchange Rates and the Pattern of Trade: Comparative Dynamics for North and South, Journal of International Money and Finance 15, 313-336.

[10] Goldberg, Linda, and Jose Campa, 2000, Employment versus Wage Adjustment and the U.S. Dollar, Review of Economics and Statistics, forthcoming.

[11] Goldberg, Linda, and Joseph Tracy, 2001, Exchange Rate and Wages, NBER Working Paper 8137. 
[12] Gourinchas, Pierre-Olivier, 1998, Exchange Rates and Jobs: What do We Learn from Job Flows?, NBER Macroeconomics Annual, 153-208.

[13] Grubel, Herbert, and P.J. Lloyd, 1975, Intra-Industry Trade, John Wiley \& Sons, New York.

[14] Lane, Philip, 2001, The New Open Economy Macroeconomics: A Survey, Journal of International Economics 54, 235-266.

[15] Obstfeld, Maurice, and Kenneth Rogoff, 2000a, Do we really need a New International Monetary Compact?, NBER Working Paper 7864.

[16] Obstfeld, Maurice, and Kenneth Rogoff, 2000b, New Directions for Stochastic Open economy Models, Journal of International Economics $50,117-154$.

[17] Obstfeld, Maurice, and Kenneth Rogoff, 1996, Foundations of International Macroeconomics, chapter 10, MIT press.

[18] Obstfeld, Maurice, and Kenneth Rogoff, 1995, Exchange Rate Dynamics Redux, Journal of Political Economy 103, 624-659.

[19] Rogers, John, 1997, Monetary Shocks and Real Exchange Rates, Board of Governors of the Federal Reserve, mimeo.

[20] Sarno, Lucio, 2001, Toward a New Paradigm in Open Economy Modeling: Where do We Stand?, Federal Reserve Bank of St.Louis Review, May/June 2001.

[21] Tille, Cédric, 2001, The Role of Consumption Substitutability in the International Transmission of Shocks, Journal of International Economics $53,421-444$. 
Figure 1: Sectoral specialization
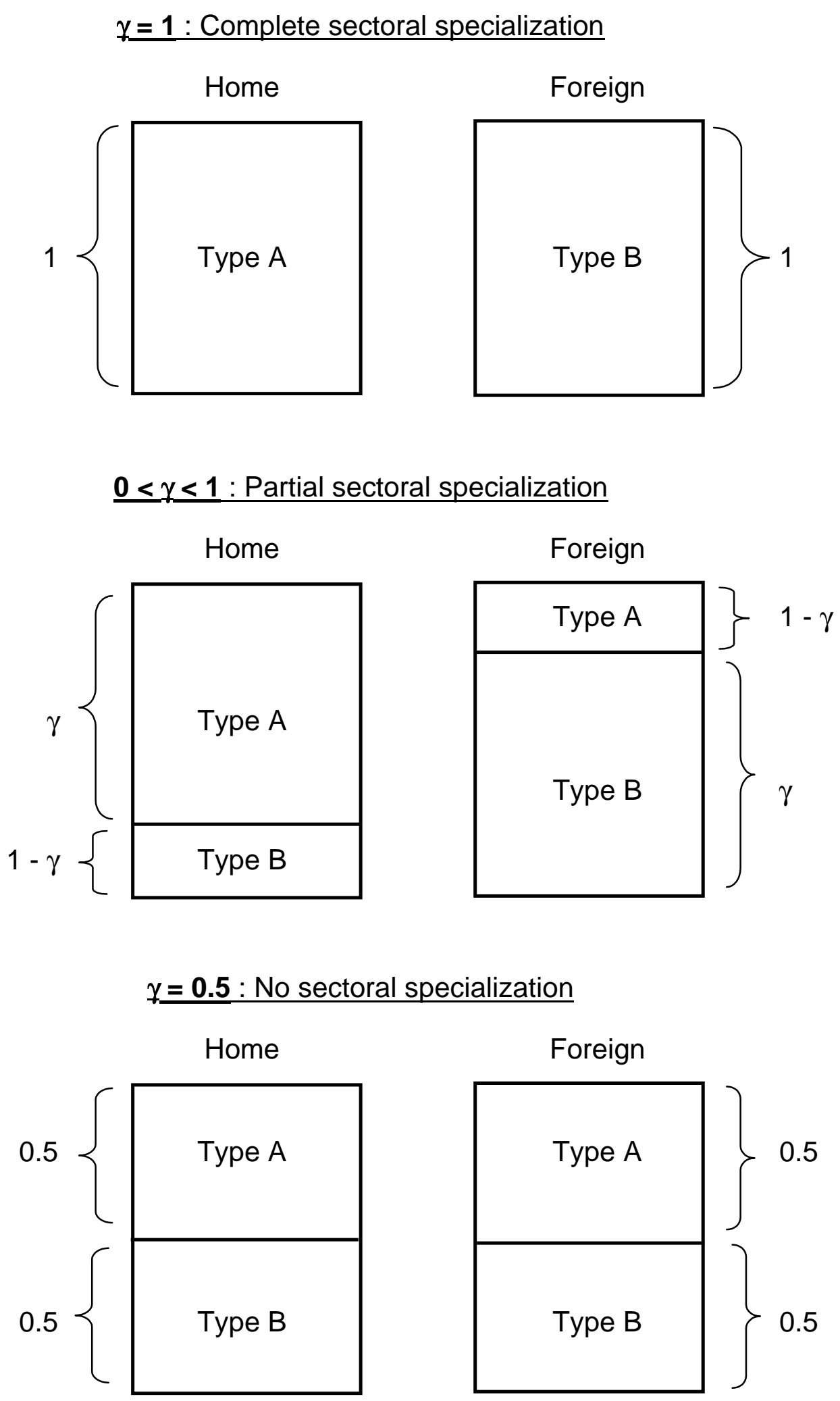


\section{Table 4: Numerical illustration: positive results}

Low substitutability across types: $\rho=1$

\begin{tabular}{|c|c|c|c|c|c|c|c|c|c|c|c|c|}
\hline \multirow[b]{2}{*}{ Household } & \multicolumn{3}{|c|}{ Output $(y)$} & \multirow[b]{2}{*}{$\gamma=1$} & \multicolumn{4}{|c|}{ Consumption (c) } & \multicolumn{3}{|c|}{ Short run savings $(b)$} & \multirow[b]{2}{*}{$\gamma=1$} \\
\hline & $\gamma=0.5$ & $\gamma=0.75$ & $\gamma=0.95$ & & $\gamma=0.5$ & $\gamma=0.75$ & $\gamma=0.95$ & $\gamma=1$ & $\gamma=0.5$ & $\gamma=0.75$ & $\gamma=0.95$ & \\
\hline Home: & & & & & & & & & & & & \\
\hline Type A & 3.04 & 2.04 & 1.23 & 1.00 & 0.58 & 0.54 & 0.51 & 0.50 & 2.04 & 1.06 & 0.23 & 0.00 \\
\hline Type B & 3.04 & 4.25 & 5.58 & & 0.58 & 0.62 & 0.66 & & 2.04 & 3.19 & 4.43 & \\
\hline Average & 3.04 & 2.59 & 1.44 & 1.00 & 0.58 & 0.56 & 0.52 & 0.50 & 2.04 & 1.59 & 0.44 & 0.00 \\
\hline Foreign: & & & & & & & & & & & & \\
\hline Type A & -2.04 & -3.25 & -4.58 & & 0.42 & 0.38 & 0.34 & & -2.04 & -3.19 & -4.43 & \\
\hline Type B & -2.04 & -1.04 & -0.23 & 0.00 & 0.42 & 0.46 & 0.49 & 0.50 & -2.04 & -1.06 & -0.23 & 0.00 \\
\hline Average & -2.04 & -1.59 & -0.44 & 0.00 & 0.42 & 0.44 & 0.48 & 0.50 & -2.04 & -1.59 & -0.44 & 0.00 \\
\hline
\end{tabular}

High substitutability across types: $\rho=\mathbf{4}$

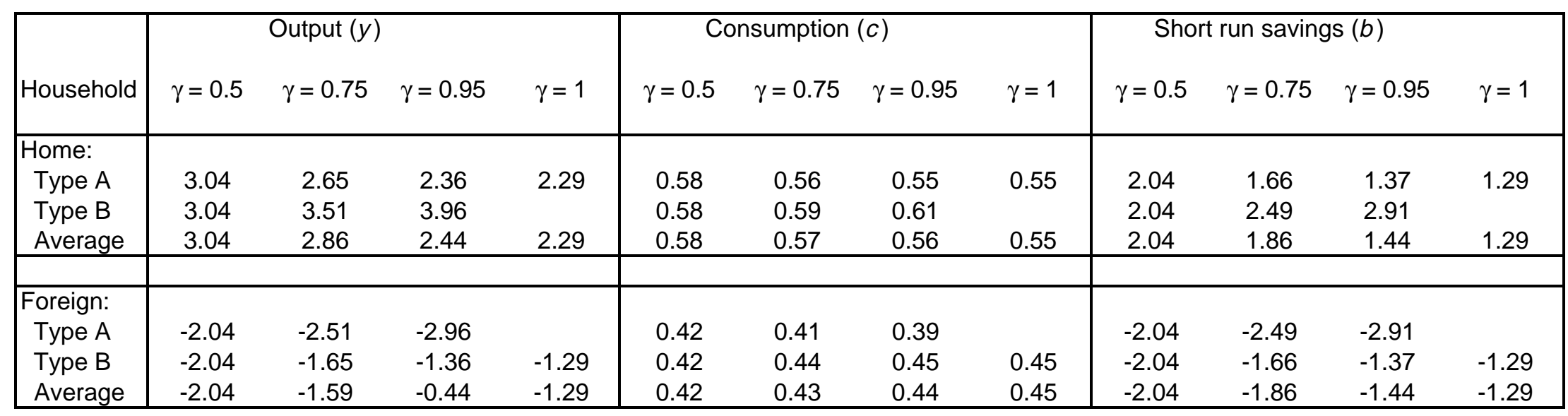

Parameters: - substitutability across brands: $\theta=6$

- discount rate: $\beta=0.94$

- monetary shock: $m=1, m^{*}=0$ 
Table 5: Numerical illustration: Normative results

Low substitutability across types: $\rho=1$

\begin{tabular}{|l|cccc|}
\hline & \multicolumn{5}{|c|}{ Welfare $(u)$} \\
Household & $\gamma=0.5$ & $\gamma=0.75$ & $\gamma=0.95$ & $\gamma=1$ \\
& & & & \\
\hline Home: & & & & \\
Type A & 0.08 & -0.10 & -0.28 & -0.33 \\
Type B & 0.08 & 0.27 & 0.45 & \\
Average & 0.08 & -0.01 & -0.24 & -0.33 \\
\hline & & & & \\
\hline Foreign: & & & & \\
Type A & 0.08 & -0.10 & -0.28 & \\
Type B & 0.08 & 0.27 & 0.45 & 0.50 \\
Average & 0.08 & 0.18 & 0.41 & 0.50 \\
\hline
\end{tabular}

High substitutability across types: $\rho=4$

\begin{tabular}{|l|llll|}
\hline & \multicolumn{5}{|c|}{ Welfare $(u)$} \\
Household & $\gamma=0.5$ & $\gamma=0.75$ & $\gamma=0.95$ & $\gamma=1$ \\
\hline Home: & & & & \\
Type A & 0.08 & 0.04 & 0.00 & -0.01 \\
Type B & 0.08 & 0.13 & 0.17 & \\
Average & 0.08 & 0.06 & 0.01 & -0.01 \\
\hline & & & & \\
\hline Foreign: & & & & \\
Type A & 0.08 & 0.04 & 0.00 & \\
Type B & 0.08 & 0.13 & 0.17 & 0.18 \\
Average & 0.08 & 0.11 & 0.16 & 0.18 \\
\hline
\end{tabular}

